\title{
Children Develop a Veil of Fairness
}

\section{Citation}

Shaw, A., N. Montinari, M. Piovesan, K.R. Olson, F. Gino, and M. I. Norton. "Children Develop a Veil of Fairness." Harvard Business School Working Paper, No. 13-003, July 2012.

\section{Permanent link}

http://nrs.harvard.edu/urn-3:HUL.InstRepos:9299652

\section{Terms of Use}

This article was downloaded from Harvard University's DASH repository, and is made available under the terms and conditions applicable to Other Posted Material, as set forth at http:// nrs.harvard.edu/urn-3:HUL.InstRepos:dash.current.terms-of-use\#LAA

\section{Share Your Story}

The Harvard community has made this article openly available.

Please share how this access benefits you. Submit a story.

Accessibility 
H A R V A R D

\section{Children Develop a Veil of Fairness}
A. Shaw
N. Montinari
M. Piovesan
K.R. Olson
F. Gino
M.I. Norton

\section{Working Paper}

13-003

July 11, 2012 
Running head: Veil of Fairness

Children develop a veil of fairness

A. Shaw, ${ }^{* 1}$ N. Montinari* ${ }^{2}$, M. Piovesan, ${ }^{3}$ K.R. Olson, ${ }^{1}$ F. Gino, ${ }^{3}$ and M.I. Norton ${ }^{3}$

${ }^{1}$ Yale University, 2 Hillhouse Ave, New Haven, CT 06520, ${ }^{2}$ Max Planck Institute of

Economics, Kahlaische Straße 10, D-07745 Jena, Germany, and ${ }^{3}$ Harvard Business School, Soldiers Field Road, Boston, MA 02163.

* Indicates co-first author.

Acknowledgements: This research was supported by a grant from the University of Chicago’s ARETE Initiative/A New Science of Virtue Program. The authors would like to thank Alia Martin, Felix Warneken, Peter Blake, \& Matthias Sutter, and the members of our lab groups for their comments on a previous draft. We would also like to thank Anna Merrill for running many of the participants in these studies.

Correspondence concerning this article should be addressed to Alex Shaw, Department of Psychology, Yale University, 2 Hillhouse Avenue, New Haven, CT 06520. Email: Alex.Shaw@yale.edu 


\begin{abstract}
Previous research suggests that children develop an increasing concern with fairness over the course of development. Research with adults suggests that the concern with fairness has at least two distinct components: a desire to be fair but also a desire to signal to others that they are fair. We explore whether children's developing concern with behaving fairly towards others may in part reflect a developing concern with appearing fair to others. In Experiments 1-2, most 6- to 8year-old children behaved fairly towards others when an experimenter was aware of their choices; fewer children opted to behave fairly, however, when they could be unfair to others yet appear fair to the experimenter. In Experiment 3, we explored the development of this concern with appearing fair by using a wider age range (6- to 11-year-olds) and a different method. In this experiment, children chose how to assign a good or bad prize to themselves and another participant by either unilaterally deciding who would get each prize or by using a fair procedure - flipping a coin in private. Older children were much more likely to flip the coin than younger children, yet were just as likely as younger children to assign themselves the good prize by reporting winning the coin flip more than chance would dictate. Overall, the results of these experiments suggest that as children grow older they become increasingly concerned with appearing fair to others, which may explain some of their increased tendency to behave fairly.
\end{abstract}

Keywords: fairness, inequity aversion, reputation, social signaling, social cognitive development 


\section{Children develop a veil of fairness}

Fairness is an important feature of human resource sharing that promotes unselfish behavior in a wide range of contexts (Blau, 1964; Fehr \& Schmidt, 1999; Organ, 1988). Concerns with fairness appear in nearly every culture in the world, even in small hunter-gatherer societies (Boehm, 2008; Gurven, 2004; Henrich, 2004). As a result, scholars across disciplines, from economics to neuroscience to psychology, have long been interested in the study of fairness, with a large body of research suggesting that humans respond negatively to violations of fairness and are even willing to assume personal costs to avoid unfairness (Adams, 1965; Dawes, Fowler, Johnson, McElreath, \& Smirnov, 2007; Fehr, Goette \& Zehnder, 2009; Kahneman, Knetsch, \& Thaler, 1986). This willingness to incur costs to avoid unfairness appears to develop over the course of childhood, with three-year-olds being very unwilling to incur costs in order to be fair whereas eight-year-olds are willing to do so (for a review see Hook \& Cook, 1979). Fehr, Bernhard, and Rockenbach (2008) have argued that this developmental shift indicates that children develop a preference for fair outcomes throughout childhood.

At the same time, however, other research has shown that people often act to create an appearance of fairness without actually bearing the costs of being so (Batson, Kobrynowicz, Dinnerstein, Kampf, \& Wilson, 1997). For instance, adults will opt into a fair procedure over an unfair one in public settings, but honor the outcome of that fair procedure only if it favors them (Batson et al., 1997). More generally, people tend to behave considerably less fairly when they can do so without appearing unfair (Andreoni \& Bernheim, 2009; Dana, Weber, \& Kuang, 2007; Levitt \& List, 2007; Reis \& Gruzen, 1976). Taken together, these streams of research highlight an important distinction between being fair and appearing fair to others. Children are also concerned with how they appear to others, with children's tendency to engage in self- 
presentation increasing as they approach eight to ten years of age (Aloise-Young, 1993;

Apfelbaum, Pauker, Ambady, Sommers, \& Norton, 2008; Banerjee, 2002; Piaget, 1932; Selman, 1980; Turiel, 2006). Interestingly, children become increasingly concerned with how they appear to others at the same time as they are becoming more concerned with being fair.

In this paper, we explore whether previous research with children documenting the development of a desire to be fair instead may be partly assessing the development of a desire to appear fair. Across three experiments, we investigate whether children, like adults, attempt to appear fair without being fair in some contexts - developing an appreciation of the usefulness of cloaking unfair decisions under a veil of fairness.

\section{Being Fair versus Appearing Fair}

Two broad classes of models have been proposed to explain why adults act fairly: social preference models and social signaling models. Social preference models propose that people like, or have a preference for, fairness and, just like with other preferences, say for caviar or fancy wine, people are willing to pay (costs) to satisfy this preference (Adams 1965; Bolton \& Ockenfels, 2000; Fehr \& Schmidt 1999). These models suggest that when people generously share or fairly split their resources with others they are demonstrating their preference for fair outcomes over selfish alternatives. In contrast, social signaling models propose that people's motivation underlying these same actions is a desire to demonstrate to others that they are fair, rather than a desire to actually be fair. People frequently engage in behaviors that allow them to appear nice, altruistic, and fair to others (Barclay \& Willer, 2007; De Cremer \& Sedikides, 2008; Kahn \& Young, 1973; Latane, 1970; Milinski, Semmann, \& Krambeck, 2002; Reis \& Gruzen, 1976); such self-presentation or impression management is a ubiquitous aspect of social interaction (Baumeister, 1982; Leary, Allen, \& Terry, 2011; Leary \& Kowalski, 1990). Social 
signaling models therefore predict that individuals should be less willing to pay costs in order to be fair if their unfair behavior is unlikely to be discovered by others (Andreoni \& Bernheim, 2009; Dana et al., 2007) - that individuals do not prefer fair outcomes per se, but merely that others think that they are fair. Obviously people could, in theory, have both a social preference for fairness and a desire to appear fair to others.

However, these two models differ in the extent to which transparency—or the degree to which others are aware of one's fair and unfair behavior (Dana et al., 2007)—should influence one's behavior. According to social preference models, transparency should not affect behavior that is based on social preferences; the preference for fairness should hold regardless of whether one’s decisions are observed by others (Fehr \& Schmidt, 1999). In contrast, signaling models predict that transparency will exert an impact on behavior precisely because other people's knowledge is driving people's fairness-oriented behavior; insofar as others believe that an individual is being fair, actually behaving fairly is irrelevant (Andreoni \& Bernheim, 2009). Supporting the latter models, adults often behave less fairly if they can be unfair without looking unfair to others (Dana et al., 2007; Kagel, Kim, \& Moser, 1996, Larson \& Capra, 2009; Levitt \& List, 2007; Reis \& Gruzen, 1976). Appearing fair without actually being fair can also be achieved by obscuring the fact that one decided to be unfair or by leading others to believe that a fair procedure was used to determine how resources are allocated, even if a fair procedure was not actually used (Batson, Thompson, \& Chen, 2002; Dana et al., 2007; Dana, Cain, \& Dawes, 2006; DeScioli, Christner, \& Kurzban, 2011).

In one elegant paradigm, Batson and colleagues (2002) demonstrated that individuals use seemingly impartial procedures to appear fair to others while being unfair. In their experimental paradigm, participants had to assign a good task and a bad task to themselves and another 
participant, and could either simply choose the task they wanted for themselves or use a fair procedure (flipping a coin) to assign the tasks. If participants chose the fair procedure, they flipped the coin in private and then reported the task assignment to the experimenter. Half of the participants were unfair by selfishly choosing the better option for themselves, whereas the other half flipped the coin. However, of those who opted to flip the coin, the majority still assigned themselves to the good task and the other participant to the bad task, suggesting that they ignored the result of the coin flip. Flipping the coin and then being unfair by lying about the outcome of the coin flip is a result predicted by social signaling models: individuals who flip the coin appear fair to the experimenter (achieving social signaling) while fulfilling their selfish desire to be assigned to the good task. Such behavior is not consistent with social preference models, which would predict that people who have social preferences for fairness would flip the coin and abide by the outcome. In sum, research on adults suggests that people are motivated by social signaling and sometimes use strategies to avoid being fair if they can still appear fair.

\section{A developing sense of wanting to appear fair?}

If fairness is partly rooted in a human desire to present oneself in a favorable light, then we might be able to find evidence for social signaling even in young children. Interestingly, however, the bulk of research on fairness in children has not focused on documenting children's desire to appear fair, but instead focuses on investigating the development of their actual taste for fairness. Considerable research has suggested that children are concerned with fairness. For example, 16- to 19-month-old infants gaze longer when resources are distributed unequally between two recipients, and prefer fair over an unfair people (Geraci \& Surian, 2011; Schmidt \& Sommerville, 2011; Sloane, Baillargeon, \& Premack, 2012). In the preschool years, children allocate resources equally between recipients when possible (Damon, 1977; Hook \& Cook, 1979; 
Olson \& Spelke, 2008; Sigelman \& Waitzman, 1991). Between the ages of 6 and 8, children will sacrifice their own resources in order to be fair (Blake \& McAuliffe, 2011; Shaw \& Olson, 2012). While these studies have demonstrated that children behave fairly, they have left unanswered a critical question: whether children's fair behavior is partly motivated by a desire to appear fair to observers as a form of self-presentation. In most of these experiments, an experimenter had full knowledge of children's decisions - muddying the true nature of children's fairness decisions.

Importantly, research does suggest that by age 8 children do understand and care about self-presentation. Between the ages of 9 and 11, children employ self-promotional strategies to influence the impressions they make on those around them (Aloise-Young, 1993) and are aware that others engage in self-presentation as well (Bennett \& Yeeles, 1990). They further appreciate that certain traits are more desirable than others depending on the audience- - they know that they should behave differently to impress their peers than to impress an adult (Banerjee, 2002). Around the same age, children understand that not only one's actions, but also what others say about one's actions, can influence how one is seen by a peer group (Hill \& Pillow, 2006; Houser, Montinari, \& Piovesan, 2012). Additionally, children in Western society recognize that expressing negative racial attitudes or even acknowledging racial differences can reflect poorly on them and so they learn to inhibit their judgments based on race between the ages of 8 and 10 years old (Apfelbaum et al., 2008; Rutland, Cameron, Milne, \& McGeorge, 2005). Taken together, these studies suggest that, around age 8 or 9 , children have an understanding of the factors that go into impression formation, modify their own behaviors, and know that others should modify their behaviors in service of appearing favorably to others. 
In sum, children's concern with being fair follows a developmental time course that is similar to the development of concerns with self-presentation, with both concerns strongly present by age 8 years old. We explore whether previous research with children documenting the development of concerns about being fair may be at least in part assessing the development of concerns about appearing fair. Indeed, some initial evidence is consistent with this claim. Children aged 6 to 14 years old are more generous when a recipient (a classmate) can view their decision (Buhrmester, Goldfarb, \& Cantrell, 1992); however, this increased generosity may be due merely to the desire to avoid negative emotional reactions from that specific recipient - say, tears and anger. In our experiments, we ensure that recipients are not present and a third party observer is, allowing us to specifically investigate children's motivation to appear fair to third parties rather than merely to avoid negative reactions from recipients.

\section{Overview of the present research}

Across three experiments, we examine whether children's fair behavior is motivated by a preference for fair outcomes or a desire to demonstrate their fair behavior to others. We first investigate whether children are influenced by transparency, and then whether or not children develop the tendency to cloak their unfair decisions under a veil of fairness - becoming more likely as they age to choose procedures that allow them to be unfair without appearing unfair to others. In Experiments 1 and 2 we investigate if children are willing to be less fair to others when they believe an experimenter will not know they are being unfair and when they can gain resources for themselves by being unfair. We predict that, as in previous research, children will be fair when their allocation decisions will be transparent to others. However, consistent with social signaling models, we predict that children will be systematically less fair when this transparency is decreased. 
In Experiment 3, we investigate children's tendency to be unfair without appearing unfair by running a conceptual replication of Batson and colleagues (2002) with children rather than adults; most importantly, we investigate whether the tendency to cloak decisions under a veil of fairness increases over the course of childhood, from ages 6 to 11 years old. Our goal was to investigate whether children would choose a fair procedure (flipping a coin) to appear fair but then lie about the outcome, if needed, so that they could receive the more attractive option. Based on research showing that children are concerned with fairness in this age range and research demonstrating that self-presentation concerns increase as children grow older, we predicted that the likelihood of choosing coin flipping would increase with age - reflecting children's increased desire to appear fair. In contrast, we predicted no difference by age in children's tendency to give themselves a more attractive outcome regardless of the outcome of the coin flip - their desire to actually be fair.

\section{Experiment 1}

To investigate whether children’s behavior is motivated partly by a desire to appear fair, we varied what children thought an experimenter knew in three conditions (for similar manipulations of others' knowledge in adults, see Dana et al., 2007; Guth, Huck, \& Ockenfels, 1996). In the first condition, children were presented with a choice of allocating a resource in a way that was fair or unfair, in an environment in which the experimenter had full knowledge of the resulting (in)equality. In the other two conditions, the experimenter had mistaken information about the number of resources that either the participant or another recipient had. Participants had a chance to decide whether to allocate a resource in a fair way or in an unfair way. The unfair option either benefitted the participant or another recipient.

We investigated 6- to 8-year-old children because previous research has suggested that 
children in this age group demonstrate fair behavior (Hook \& Cook, 1979,). Though younger children can recognize and correct unfair outcomes (Geraci \& Surian, 2011; LoBue, Nishida, Chiong, DeLoache, \& Haidt, 2011) they do not show a robust willingness to incur costs to avoid unfairness until between the ages of 6 to 8 years old (Blake \& McAuliffe, 2011; Hook \& Cook, 1979; Shaw \& Olson, 2012).

In order to investigate if children were specifically concerned with appearing fair we used a recent measure of fairness developed by Shaw and Olson (2012), a measure that does not conflate fairness with generosity (Charness \& Rabin, 2002). In typical tasks used to measure fairness, an individual is given some resources and asked whether she wants to selfishly keep more for herself or share them with another person (Fehr \& Schmidt, 1999; Sigelman \& Waitzman, 1991). A willingness to share resources with others in such a case is thought to evidence a concern with fairness, but it could also indicate that the individual is generous. In order to measure fairness specifically, Shaw and Olson (2012) presented children with a situation in which fairness and generosity predicted different behaviors. Specifically, a situation in which there was an equal distribution of resources and participants were asked if they wanted to give an additional resource to themselves or throw the resource in the trash (or in another condition if they wanted to give an additional resource to one of two third-party recipients or throw the resource in the trash). In this task, taking more for oneself (or giving out an additional resource to one of the recipients) did not involve imposing costs on others since the resource would be thrown in the trash if it was not given out. Despite this, Shaw and Olson (2012) found that children opted for fairness, throwing a resource in the trash in order to avoid inequality (for a similar measure of fairness in adults, see Shaw \& Knobe, in press). Here we investigate if this sense of fairness, separate from generosity, is partly motivated by self-presentational concerns- 
would children be less likely to be fair in this way if an experimenter did not know they had been unfair.

$\underline{\text { Method }}$

Participants. Participants included sixty children aged 6 to 8 years: 20 in the Transparent Self Condition ( $M=7$ years, 3 months; $S D=7.5$ months; 11 females), 20 in the Opaque Self Condition ( $M=7$ years, 3 months; $S D=10$ months; 15 females), and 20 in the Opaque Other Condition ( $M=7$ years, 2.5 months; $S D=10.5$ months; 11 females $)$.

Procedure. Children were first asked some unrelated questions so that they could be rewarded with erasers and were then assigned to one of three conditions. In the Transparent Self Condition (a conceptual replication of Study 4 in Shaw \& Olson, 2012), the participant was told that she and another non-present, gender-matched recipient would each be given some erasers as a prize for answering the initial questions and that these erasers would be placed on top of envelopes with their names on them. The participant and the non-present recipient were then each given two erasers on top of their envelopes. The experimenter said that she forgot an eraser in the other room and then went to get the eraser. When the experimenter returned with the additional eraser (within a minute of leaving the room), the experimenter asked the participant if she should give the eraser to the participant or throw it away.

In the Opaque Self Condition, children were provided with the opportunity to be unfair without appearing unfair. In this case, the participant was given one eraser and the other nonpresent recipient was given two erasers; the erasers were placed inside of the envelopes. The experimenter then said she forgot an eraser in the other room and went to get it. When the experimenter was gone a confederate entered the room and gave the child an additional eraser. The confederate then said: “Shh, don't tell (experimenter’s name)” and left the room. The 
confederate's line was added so that children did not spontaneously mention that they had been given an extra eraser before they were given the option to take an eraser or throw it away. The experimenter returned and then asked the participant if the experimenter should give the extra eraser to the participant or throw the eraser away. As in the previous condition, at the time the choices were presented to the participant, both the participant and the non-present recipient had two erasers.

The Opaque Other Condition served as a control for the confederate entering the room and saying "shh". We did this because it was possible that just having the confederate say "shh" and give an additional eraser may have prompted children to behave differently, e.g. in order to not tattle on the confederate. In this condition, the non-present recipient was the one to receive only one eraser in their envelope while the child participant received two. Again the experimenter left the room and the confederate came in, this time placing an extra eraser in the non-present recipient’s envelope and saying “Shh, don’t tell (experimenter’s name)”. When the experimenter returned, she asked if she should give the eraser to the non-present recipient or throw it away.

We decided to have the experimenter be the potential audience for children’s fair behavior since the experimenter is often the only person present in many experiments on fairness in children (Fehr et al., 2008; Hook \& Cook, 1979; Shaw \& Olson, 2012; Sigelman \& Waitzman, 1991). We wanted to investigate if wanting to appear fair to an experimenter motivates part of children's fair behavior in these contexts. We chose this option rather than having the recipient be the audience because in cases where the recipient is present (Blake \& McAullife, 2011; Buhrmester et al., 1992), there is always the worry that children will be fair simply in order to avoid negative reactions or scorn from a potential recipient rather than to appear fair. 


\section{$\underline{\text { Results }}$}

A binomial test on the Transparent Self Condition revealed that children opted to be fair by throwing the eraser in the trash $(80 \%)$ rather than taking it for themselves, $p=.012$. In contrast, a binomial test on the Opaque Self Condition revealed that children opted to be fair by throwing the eraser in the trash (25\%) at below chance levels, $p=.041$. That is, when children no longer risked appearing unfair they were substantially less fair. Indeed, a Yates-corrected chisquare test revealed that children behaved significantly differently in these two conditions, $\chi^{2}$ $(2, N=40)=10.03, p=.002$. A binomial test on the Opaque Other Condition revealed that children showed no preference for being fair (60\% threw the eraser away) over being unfair and keeping the eraser for themselves, $p=.503$. A Yates-corrected chi-squared test revealed that children were (marginally) more likely to be unfair in the Opaque Self Condition than in the Opaque Other Condition, $\chi^{2}(2, N=40)=3.68, p=.055$ (see Figure 1). This result suggests that children did not act unfairly in the Opaque Self Condition simply to avoid tattling on the confederate, since the action of the confederate was held constant across these conditions.

\section{$\underline{\text { Discussion }}$}

These results indicate that children's fair behavior is partly driven by wanting to appear fair to an experimenter since children were less fair when they could be unfair without the experimenter knowing. When everything was out in the open, children sacrificed a resource in order to uphold fairness. However, when children could appear fair, but actually be unfair in a way that favored them, children chose this option, something they did not do when someone else stood to gain from the unfairness.

One concern about our method is that the use of the word "shh" by the confederate in the Opaque conditions may have incentivized children to be unfair, not because they wanted to be 
unfair but because they were afraid of tattling on the confederate. Although this explanation could account for the overall lower rates of fair behavior in the Opaque conditions, it cannot explain why children were less fair in the Opaque Self Condition as compared to the Opaque Other Condition since the worry about informing on the confederate was present in both conditions. The only difference between these two conditions was whether the unfairness benefited the child or not. When they benefited from the unfairness, children were more unfair than they were when the unfairness benefitted someone else. Therefore, even though we did not ask children why they were fair, we can infer that our manipulation was what caused the different behavior in these two conditions.

The difference between conditions could be explained in at least two ways. One explanation is that children sometimes inhibit their desire to unfairly take more resources for themselves when others will know they have been unfair and that by changing what the experimenter knew, we allowed children to be unfair since the experimenter would not know. A second explanation is that children were primed to be sneaky or underhanded by being exposed to a confederate who said "shh". This prime could have caused children to be more unfair than they normally would be. Additionally, if one adds an assumption that priming sneakiness is more likely to cause a child to be unfair in ways the benefit herself, this could potentially explain our results. If the second explanation is correct, then removing these factors that primed sneakiness should cause children to be fair once again. In Experiment 2 we manipulate transparency without using a confederate or the word "shh", which should eliminate this concern with priming sneakiness.

\section{Experiment 2}

In Experiment 2 we investigated whether children’s concerns with fairness are influenced 
by an even more subtle manipulation of transparency: providing an opportunity for plausible deniability by introducing ambiguity about how many erasers the recipients had. In the two critical new conditions, we varied whether the participant herself or a non-present recipient would potentially benefit from the plausible deniability. Importantly, this manipulation of transparency did not include an additional confederate or the word "shh,” potential concerns from Experiment 1.

$\underline{\text { Method }}$

Participants. Participants included sixty children aged 6 to 8 years: 20 in the Transparent Self Condition ( $M=7$ years, 2 months; $S D=11$ months; 11 females), 20 in the Plausible Deniability Self Condition ( $M=7$ years, 4.5 months; $S D=11$ months; 10 females), and 20 in the Plausible Deniability Other Condition ( $M=7$ years, 3 months; $S D=12$ months; 10 females).

Procedure. Children completed an unrelated task so that they could be rewarded with erasers. In the Transparent Self Condition, an exact replication of the Transparent Self Condition from Experiment 1, the participant and another non-present, gender-matched recipient each received some erasers on top of their envelopes (two erasers each). As in Experiment 1, the experimenter left the room and returned, and the participant then had to decide if she wanted to keep an additional eraser for herself or throw it away. The erasers were on top of the envelopes (in plain sight) throughout the experiment.

The procedure for the Plausible Deniability Self condition was the same as in the Transparent Self Condition except that the erasers were placed inside the envelopes. Putting the erasers inside the envelopes could create plausible deniability in two ways. First, children could have felt licensed to be unfair because they thought the experimenter forgot how many erasers they had. Second, if the experimenter did notice that they had been unfair, children could claim 
that they had forgotten how many erasers they had. Therefore, by placing the erasers inside the envelopes we allowed children the possibly of being unfair (giving an additional eraser to themselves and creating inequality) without necessarily appearing unfair. Of course, children could actually forget how many erasers were in their envelope. To be certain this was not the case, a third group of children was assigned to the Plausible Deniability Other Condition, which was the same as the Plausible Deniability Self Condition except that both recipients were now non-present children (Mark/Mary and Dan/Danielle, gender-matched to the participant) who were being rewarded for doing a good job answering questions. Thus, when the experimenter returned she asked if she should give the eraser to Mark/Mary or if she should throw it away. If children in the Plausible Deniability Self Condition forgot how many erasers were inside the envelopes, then they should also forget in this case because the erasers were again inside the envelopes. However, we predicted that they would not forget how many erasers were in the envelopes and in this case would say to throw the erasers away.

$\underline{\text { Results }}$

A binomial test on the Transparent Self Condition revealed that children opted to do what was fair by throwing the eraser in the trash (85\%) rather than taking it for themselves, $p=.003$. A binomial test on the Plausible Deniability Self Condition revealed that children showed no preference for doing what was fair (45\% threw the eraser away), $p=.82$. A Yates-corrected chisquare test revealed that children were significantly less likely to do what was fair (i.e., they were more likely to take the eraser for themselves) in the Plausible Deniability Self Condition as compared to the Transparent Self Condition $\chi^{2}(2, N=40)=5.39, p=.020$. A binomial test on the Plausible Deniability Other Condition revealed that children were more likely to be fair ( $80 \%$ ) by throwing the eraser in the trash rather than giving it to the non-present recipient, $p=.012$. A 
Yates-corrected chi-squared test revealed that children were more likely to do what was fair in the Plausible Deniability Other Condition than they had been in the Plausible Deniability Self Condition $\chi^{2}(2, N=40)=3.84, p=.05$.

\section{$\underline{\text { Discussion }}$}

As in Experiment 1, children opted to be fair rather than appear fair when all resources were out in the open; however, when resources were hidden, creating some plausible deniability, children unfairly accepted an extra resource for themselves more often than when things were transparent. This result suggests that part of the reason children are fair when everyone has full knowledge is to avoid appearing unfair to an experimenter since children were substantially less fair when there was some doubt about whether or not the experimenter would know the child had been unfair.

Our results cannot be explained by children being unable to track how many erasers were in the envelopes when the resources were hidden. The only difference between the Plausible Deniability Self Condition and the Plausible Deniability Other Condition is whether the eraser was going to the participant herself or to someone else. Yet, in the Plausible Deniability Other Condition children were able to keep track of how many erasers were in each of the envelopes and did what was fair. Since children could keep track of how many erasers were in each envelope in this third party condition, we can presume that they could do this equally well in the case where they were one of the recipients. This suggests that children were not confused in the Plausible Deniability Self condition and instead took advantage of the plausible deniability to take more for themselves.

Importantly, these results suggest that children are influenced by transparency even in the absence of behaviors that prime sneakiness. In the plausible deniability conditions of Experiment 
2 there was no confederate, no one said "shh", and the experimenter did not even make note of that fact that the erasers were inside envelopes. Yet children still modified their behavior based on the lack of transparency. This result allays the concern from Experiment 1 that children were only being unfair because they were primed to be sneaky. These results instead favor the interpretation we propose, which argues that children are less fair in these non-transparent cases because they can be unfair without appearing unfair to an experimenter.

Now that we discovered that children are motivated to appear fair using the paradigm from Shaw and Olson (2012), we wanted to investigate if children are also motivated to appear fair and unselfish to others in a task that has been used with adults. In Experiment 3, we conducted a conceptual replication of Batson and colleagues' (2002) adult work on people’s willingness to be unfair while still appearing fair to others.

\section{Experiment 3}

In Experiment 3 we examined whether children are concerned with appearing fair to others using a different procedure and also examined if children's willingness to use procedures that obfuscate their unfairness from others - the veil of fairness - increased with age. Here children could assign themselves a good prize or a bad prize. They were given the option of simply choosing which prize they wanted or flipping a coin behind a curtain and then telling the experimenter whether they had won the good prize or the bad prize. We predicted that children, like adults (Batson et al., 2002), would choose a seemingly fair procedure (flipping a coin) to appear fair but then lie about the outcome, if needed, so that they could receive the more attractive option without appearing unfair to others.

We also added an older age group because previous research had indicated that 9- to 11year-old children show increased awareness of self-presentational strategies (Banerjee, 2002). 
We predicted that the likelihood of choosing the seemingly fair procedure (coin flipping) would increase with age - reflecting children's increased awareness that they could use this procedure to appear fair without having to pay the cost. However, based on our previous experiments, we predicted that children at all ages would be just as likely to lie and give themselves the better option when they did opt to flip the coin—when they could be unfair without appearing unfair. $\underline{\text { Method }}$

Participants. Participants included 566 children aged 6 to 11 years $(M=8$ years, 9 months; $S D=1$ year and 4 months; 279 females). The children were from 41 classes across ten schools in the district of Treviso, in Italy.

Procedure. Each child was asked to assign a prize to themselves and a prize to another person: a good prize (a colored highlighter pencil, labeled “Prize A”) or a bad prize (a normal pencil, labeled “Prize B”). Children were presented with two options regarding the procedure to use for the prize assignment: taking the prize that they liked better immediately, or flipping a coin in private to decide. Children chose between these two options in front of the experimenter, but the option they chose was not revealed to any other child in the classroom. Children who chose to flip the coin were asked to flip the coin only once behind a screen, in a place both visually and acoustically isolated that assured their privacy, and then fill out a sheet to indicate the outcome. After flipping the coin and indicating the outcome, children returned both the coin and the report sheet to the experimenter. The outcome of the flip was both self-reported and in private to give children the opportunity to report that they won the good prize even if they lost the coin flip.

\section{$\underline{\text { Results }}$}


Across our analyses, we use age as our main independent variable. We divided children into two groups of three-year increments: we included the 6- to 8-year-old age group we had tested in our previous experiments and an older 9- to 11-year-old age group.

We first had to determine if children really did prefer the good prize, so we examined what children chose when they opted not to flip the coin. A binomial sign test on those children who immediately chose a prize rather than flipping the coin, revealed that children were more likely to choose the good prize (89.5\%) than the bad one, $p<.001$. This was true for both 6 - to 8year-olds (89.5\%), $\mathrm{p}<.001$ and 9- to 11-year-olds (89.5\%), $p<.001$. Importantly, these results did not differ across age groups $\left(\chi^{2}\right.$ test, $\left.p=1.000\right)$. Thus both age groups were equally likely to desire the good prize more than the bad prize - and thus children who did opt to flip the coin would be motivated to misreport the results of the fair coin flip to obtain the good prize.

We then examined whether age predicted the likelihood of choosing the fair procedure flipping a coin - to determine the assignment of the two prizes. A Logit regression revealed that children's age predicted the choice to flip ( $\mathrm{B}=.66, \mathrm{SE}=.22)$; as age increased, the percentage of children choosing to flip the coin increased significantly, from 36.9\% for 6- to 8-year-olds to 53.2\% for 9- to 11- year-olds (see Figure 2), Mann-Whitney test, $p<.001$. But does this preference reflect a real concern with being fair, or just a concern with appearing fair as we predicted?

We now turn to analyses of what the children reported after they flipped the coin. Would older children - who previous research suggests have developed a concern for fairness - be more likely to resist this urge to unfairly take the better prize for themselves and fairly report the outcome of the coin flip? Among children who chose to flip the coin, $62.2 \%$ reported winning the good prize, a percentage significantly greater than 50\% $(p<0.001)$ - the percentage of good 
prizes that a fair coin would have caused them to actually win. Interestingly, and in line with our hypotheses, this result did not differ across age groups $\left(\chi^{2}=0.136 p=0.712\right)$. Children in both age groups were likely to report winning at levels above what one would expect by chance, $60.7 \%$ for the 6- to 8-year-old age group; $63.0 \%$ for the 9- to11-year-old age group, (all ps < 0.003; see Figure 2).

Discussion

Taken together we found converging evidence, using a different paradigm, that children’s fair behavior is at least partly motivated by a desire to appear fair to others. Many children chose to flip a coin rather than selfishly taking the better reward for themselves, but of those who chose this fair option some ignored the outcome of the coin and just gave themselves the better reward. We further found that children's willingness to utilize this seemingly fair coin flip increased with age. That is, all children were equally likely to be unfair once they decided to use the seemingly fair procedure, but older children may have felt a greater pressure to use the coin flip because they were more concerned with appearing unfair to the experimenter if they did not use the coin flip.

Alternatively, children may have initially decided to flip the coin and planned to be fair, but changed their mind after they were given time to think about their decision. If this alternative explanation were correct, then we should expect the same pattern of results if the child is first left alone and then later is given the choice to flip the coin in front of the experimenter. This does not appear likely, but we cannot rule out this explanation based on the data from Experiment 3. However, this explanation based on children changing their mind cannot account for the results from Experiments 1 and 2 because children were given the same time to think in all conditions and still opted to be unfair when transparency was obscured. Therefore, we support the 
interpretation that offers the most parsimonious account for the three studies we described—that children are more unfair when they can be unfair without appearing unfair.

\section{General Discussion}

These experiments illustrate that children engage in fair behavior not only because of concerns with actually being fair, but also in order to appear fair to others. As a result, social preference models of fairness which argue that people have a taste for fair outcomes may not provide a complete picture of children's allocation behavior. Instead, children's behavior seems to be rooted partly in a motivation to present themselves favorably to others, consistent with social signaling models (Andreoni \& Bernheim, 2009). Children were more willing to assume a cost to be fair when the experimenter would know the child was being unfair than when the experimenter might not know (Experiments 1 and 2). We also found that children as young as age 6 will sometimes use an ostensibly fair procedure (i.e., flipping a coin to distribute a good vs. bad reward to themselves and a peer) in an unfair way (i.e., misreporting the result of the coin flip) in order to receive a better outcome for themselves without looking unfair. Most importantly, children were more likely to opt into this "fair" procedure as they got older (Experiment 3). Together, these results suggest that children’s fair behavior throughout middle childhood is at least partly motivated by wanting to appear fair to others. As children get older, perhaps one skill they develop is becoming savvier at determining additional strategies for achieving this goal. These results suggest that children are concerned about fairness, but will sometimes be unfair if it means they can get more for themselves - provided they can avoid the appearance of unfairness.

Our results offer support for our contention that children's behavior is driven at least in part by the desire to appear fair - but what are children trying to signal to third parties when they 
attempt to appear fair? Interestingly, children did not signal a preference for socially desirable outcomes: being fair in Experiments 1-2 required throwing resources in the trash which resulted in allocating fewer resources overall, suggesting that children were not merely trying to signal generosity to experimenters. One possibility is that appearing concerned with fairness allows people to signal to others that they are impartial (Shaw, DeScioli, \& Olson, in press). While alliances and friendships are clearly important - people’s allies preferentially favor them and will take their side in potential conflicts with others (DeScioli \& Kurzban, 2009b) - individuals also highly value impartiality and seek out impartial individuals (e.g., civil judges) to adjudicate conflicts (Tyler, 1994; Tyler \& Lind, 1992). Indeed, valuing impartiality appears to be particularly unique to human beings and is somewhat mysterious (DeScioli \& Kurzban, 2009a; in press). People may be more willing to create inequality between others and take more for themselves if this inequality is created in ways that do not imply preferential treatment or partiality (such as the outcome being determined by random chance or by the amount of work done). Importantly for this account, children and adults should especially be concerned about whether the procedure appears impartial to others. We found some support for this notion in Experiment 3, where children used a procedure that appeared impartial to others in order to assign themselves to the outcome they wanted - and did so increasingly with age. Further in support of this prediction, children demonstrate a willingness to pay costs in order to uphold fairness at about the same time developmentally (by about age 6) that children understand that one’s alliances and partiality can bias decision-making (Mills \& Grant, 2009; Mills \& Keil, 2008).

Although our results reveal that children are motivated to appear fair, they also demonstrate that some children were fair even when transparency was obscured-they still chose 
to throw away resources that could go to themselves (Experiments 1 and 2) and honestly reported the outcome of the coin flip (Experiment 3). One possible explanation for this behavior in the current experiments is that these children may have suspected that experimenters were somehow monitoring their decisions. Indeed, it may be difficult to realistically convince participants that they are not being watched inside a laboratory even if double blind procedures are used (Franzen \& Pointner, 2012). Another explanation for children’s continued fair behavior is that children in our experiments actually possess a sense of fairness that would persist even when they were convinced that no one would observe their decision (Fehr \& Schmidt, 1999). People may have a genuine sense of fairness that still influences their behavior even when no one is watching, possibly because having a sense of fairness makes one more likely to avoid negative reactions from others. Sometimes the best way to convince others that one is fair is to actually have a sense of fairness oneself (Frank, 1988). That is, people's social preferences for fairness at the proximate level may ultimately be rooted in social signaling - precisely because humans likely did not evolve to consider any interactions truly anonymous, it would have made sense to always be at least a little fair (Hagen \& Hammerstein, 2006; Shaw \& Santos, 2012). People may have mental systems that occasionally err on the side of caution and assume there is a possibility of others discovering their choices even in supposedly anonymous interactions, and so act as if someone will discover their decision (Delton, Krasnow, Cosmides, \& Tooby, 2011).

When we provided children with a seemingly impartial procedure that allowed them to appear fair to others while being selfish (Experiment 3), they took advantage of the opportunity. Future research should investigate additional strategies children might adopt when attempting to be unfair without appearing so and whether children are strategic enough to devise their own ruses for accomplishing their goal of appearing fair without being prompted to do so - as adults 
do. In order to avoid paying costs to avoid looking unfair, adults avoid interactions that might make them feel compelled to be generous (Dana et al., 2006) and strategically take more for themselves through omissions rather than commissions (Dana et al., 2007; DeScioli et al., 2011). While this concern with appearing fair may appear early in development, children likely develop more explicit strategies for avoiding the appearance of unfairness as they get older. Future developmental research should investigate if children are increasingly likely to engage in omissions and other strategies to conceal their unfairness, especially in contexts where they are concerned with presenting themselves favorably to others.

The current experiments contribute to research on children's fairness concerns by demonstrating that children modify their behavior in order to improve their reputations with third parties. Although previous studies found some evidence consistent with social signaling, they were not designed to investigate whether children want to gain a reputation with third parties as a generous versus fair individual (Buhrmester et al., 1992). In our experiments recipients were not present, allowing us to specifically investigate children's motivation to appear fair to third parties, an important step forward in understanding how children develop self-presentational concerns. This approach is more analogous to research in adult impression management, which is often focused on how individuals try to influence strangers' perceptions of them (Baumeister, 1982; Leary et al., 2011), and extends investigations of self-presentation in older children in domains other than fairness (Aloise-Young, 1993; Banerjee, 2002; Hill \& Pillow, 2006).

Finally, our research provides empirical support for the notion that people are especially likely to be unfair when there is a lack of knowledgeable oversight and when they can gain materially. If even young children can radically shift their behavior from fair to unfair based on whether authority figures are aware of their behavior, then it might be naive to believe that 
shrewd adults will be fair without similar oversight. By understanding the limitations of fairness, policy makers can discover how to leverage fairness to increase socially desirable behavior in some circumstances, while limiting its occasional wastefulness-i.e. when is causes the needless destruction of resources (Blake \& McAullife, 2011; Dawes et al, 2007; Shaw \& Knobe, in press; Shaw \& Olson, 2012). Our results suggest that fair behaviors may be driven partly by people’s desire to improve their appearance with others. In cases where appearing fair is possible without behaving fairly, troublingly, some people may focus more on the appearance than the act. 


\section{References}

Adams, J. (1965). Inequity in social exchange. In L. Berkowitz (Ed.), Advances in experimental social psychology (Vol. 2, pp. 267-299). New York: Academic Press.

Aloise-Young PA (1993) The development of self-presentation: Self-promotion in 6-to-10-yearold children. Social Cognition, 11, 201-222. doi: 10.1521/soco.1993.11.2.201

Andreoni, J., \& Bernheim, D.B. (2009). Social image and the 50-50 norm: A theoretical and experimental analysis of audience effects. Econometrica, 77(5), 1607-1636. doi:10.3982/ECTA7384

Apfelbaum, E.P., Pauker, K., Ambady, N., Sommers, S.R., \& Norton, M.I. (2008). Learning (not) to talk about race: When older children underperform in social categorization. Developmental Psychology, 44, 1513-1518. doi:10.1037/a0012835

Banerjee, R. (2002). Audience effects on self-presentation in childhood. Social Development, 11, 487-507. doi:10.1111/1467-9507.00212

Barclay, P., \& Willer, R. (2007). Partner choice creates competitive altruism in humans. Proceedings from the Royal Society, B, 272, 749-753. doi:10.1098/rspb.2006.0209

Batson, C.D., Kobrynowicz, D., Dinnerstein, J.L., Kampf, H.C., \& Wilson, A.D. (1997). In a very different voice: Unmasking moral hypocrisy. Journal of Personality and Social Psychology, 72, 1335-1348. doi:10.1037/0022-3514.72.6.1335

Batson, D., Thompson, E., \& Chen, H. (2002). Moral Hypocrisy: Addressing some alternatives. Journal of Personality and Social Psychology, 83,330-339. doi:10.1037/00223514.83.2.330

Baumeister, R. F. (1982). A self-presentational view of social phenomena. Psychological Bulletin, 91, 3-26. doi:10.1037/0033-2909.91.1.3 
Bennett, M. \& Yeeles, C. (1990). Children’s understanding of the self-presentational strategies of ingratiation and self-promotion. European Journal of Social Psychology, 20, 455-461. doi: 10.1002/ejsp.2420200507

Blake, P. R., \& McAuliffe, K. (2011). “I had so much it didn’t seem fair”: Eight-year-olds reject two forms of inequity. Cognition, 120, 215-224. doi:10.1016/j.cognition.2011.04.006

Blau, P. (1964). Justice in social exchange. Sociological Inquiry, 34, 193-206. doi:10.1111/j.1475-682X

Boehm, C. (2008). Purposive social selection and the evolution of human altruism. CrossCultural Research, 42, 319-352.

Bolton, G. E., \& Ockenfels, A. (2000). ERC: A theory of equity, reciprocity, and competition. American Economic Review, 90, 166-193. doi:10.1257/aer.90.1.166

Buhrmester, D., Goldfarb, J., \& Cantrell, D. (1992). Self- presentation when sharing with friends and non-friends. Journal of Early Adolescence, 12, 61-79. doi:10.1177/0272431692012001004

Charness, G., \& Rabin, M. (2002). Understanding social preferences withsimple tests. Quarterly Journal of Economics, 117, 817-869. doi:10.1162/003355302760193904

Damon, W. (1977). The social world of the child. San Francisco: Jossey-Bass.

Dana, J., Cain, D.M, \& Dawes, R.M. (2006). What You Don’t Know Won’t Hurt Me: Costly (But Quiet) Exit in Dictator Games. Organizational Behavior and Human Decision Processes, 100, 193-201. doi:10.1016/j.obhdp.2005.10.001

Dana, J., Weber, R., \& Kuang, J. (2007). Exploiting moral wiggle room: Experiments demonstrating an illusory preference for fairness. Economic Theory, 33, 67-80. doi:10.1007/s00199-006-0153-z 
Dawes, C., Fowler, J., Johnson, T., McElreath, R., \& Smirnov, O. (2007). Egalitarian motives in humans. Nature, 446, 794-796. doi:10.1038/nature05651

De Cremer, D., \& Sedikides, C. (2008) Reputational implications of fairness for personal and relational self-esteem. Basic and Applied Social Psychology, 30, 66-75. doi:10.1080/01973530701866557

Delton, A.W., Krasnow, M.M., Cosmides, L. \& Tooby, J. (2011). Evolution of direct reciprocity under uncertainty can explain human generosity in one-shot encounter. Proceedings of the National Academy of Sciences, 108, 13335-13340. doi:10.1073/pnas.1102131108

DeScioli, P., Christner, J., \& Kurban, R. (2011). The omission strategy. Psychological Science, 22, 442-446.

DeScioli, P. \& Kurzban, R. (in press). A solution to the mysteries of morality. Psychological Bulletin.

DeScioli, P., \& Kurzban, R. (2009a). Mysteries of morality. Cognition, 112, 281-299. doi:10.1016/j.cognition.2009.05.008

DeScioli, P., \& Kurzban, R. (2009b). The alliance hypothesis for human friendship. PLoS ONE, 4, e5802. doi:10.1371/journal.pone.0005802

Fehr, E., Bernhard, H., \& Rockenbach, B. (2008). Egalitarianism in children. Nature, 454, 1079-1083. doi:10.1038/nature07155

Fehr, E., Goette, L., \& Zehnder, C. (2009). A behavioral account of the labor market: The role of fairness concerns. Annual Review of Economics, 1, 355-384. doi:10.1146/annurev.economics.050708.143217

Fehr, E., \& Schmidt, K. M. (1999). A theory of fairness, competition, and cooperation. 
The Quarterly Journal of Economics, 114, 817-868. doi:10.1162/003355399556151

Frank, R. (1988). Passions within reason: The strategic role of the emotions. New York7 W. W. Norton \& Co.

Franzen, A. \& Pointner, S. (2012) Anonymity in the dictator game revisited. Journal of Economic Behavior and Organization, 81, 74-81. doi:10.1016/j.jebo.2011.09.005

Geraci, A. \& Surian, L. (2011) The developmental roots of fairness: Infants' reactions to equal and unequal distributions of resources. Developmental Science, 14, 1012-1020. doi:10.1111/j.1467-7687.2011.01048

Gurven, M. (2004). Reciprocal altruism and food sharing decisions among Hiwi and Ache hunter-gatherers. Behavioral Ecology and Sociobiology, 56, 366-380. doi:10.1017/S0140525X04000123

Guth, W., Huck, S., \& Ockenfels, P. (1996). Two-level ultimatum bargaining with incomplete information: an experimental study. The Economic Journal, 106, 593-604.

Hagen, E.H., \& Hammerstein, P. (2006). Game theory and human evolution: a critique of some recent interpretations of experimental games. Theoretical Population Biology, 69, 339-348. doi:10.1016/j.tpb.2005.09.005

Henrich, J. (2004). Cultural group selection, co-evolutionary processes and large-scale cooperation. Journal of Economic Behavior and Organization, 53, 3-35. doi:10.1016/S0167-2681(03)00094-5

Hill, V., \& Pillow, B. H. (2006). Children's understanding of reputations. The Journal of Genetic Psychology, 167, 137-157.

Hook, J., \& Cook, T. D. (1979). Equity Theory and the Cognitive Ability of Children. Psychological Bulletin, 86, 429-445. doi:10.1037/0033-2909.86.3.429 
Houser, D., Montinari, N., Piovesan, M. (2012) Private and public decisions in social dilemmas: Evidence from children's behavior. Working paper.

Kagel, J., Kim, C. \& Moser, D. (1996). Fairness in Ultimatum Games with Asymmetric Information and Asymmetric Payoffs. Games and Economic Behavior, 13, 100-110. doi:10.1006/game.1996.0026

Kahn, A., \& Young, D. L. (1973). Ingratiation in a free social situation. Sociometry, 36, 579-587. doi:10.2307/2786253

Kahneman, D., Knetsch, J.L. \& Thaler, R. (1986) Fairness as a constraint on profit seeking: Entitlements in the market. The American Economic Review, 76, 728-774. doi: $10.2307 / 1806070$

Larson, T., \& Capra, M. (2009). Exploiting moral wiggle room: Illusory preference for fairness? A Comment. Judgment and Decision Making, 4, 467-474.

Latane, B. (1970). Field studies of altruistic compliance. Representative Research in Social Psychology, 1, 49-61.

Leary, M. R., Allen, A. B., \& Terry, M. L. (2011). Managing social images in naturalistic versus laboratory settings: Implications for understanding and studying self-presentation. European Journal of Social Psychology, 41, 411-421. doi: 10.1002/ejsp.81

Leary, M. R., \& Kowalski, R. M. (1990). Impression management: A literature review and twocomponent model. Psychological Bulletin, 107, 34-47. doi: 10.1037/0033

Levitt, S., \& List, J. (2007). What Do Laboratory Experiments Measuring Social Preferences Tell Us About the Real World?. The Journal of Economic Perspectives, 21, 153-174. doi:10.1257/jep.21.2.153

LoBue, V., Nishida, T., Chiong, C., DeLoache, J., \& Haidt, J. (2011). When Getting 
Something Good is Bad: Even Three-year-olds React to Inequality. Social Development, 20, 154-170. doi:10.1111/j.1467-9507.2009.00560.x

Milinski, M., Semmann, D., \& Krambeck, H. J. (2002). Donors to charity gain in both indirect reciprocity and political reputation. Proceedings of the Royal Society of London. Series B, Biological Sciences, 269, 881-883. doi:10.1098/rspb.2002.1964

Mills, C. M., \& Grant, M. G. (2009). Biased decision-making: Developing an understanding of how positive and negative relationships may skew judgments. Developmental Science, 12, 784-797.

Mills, C. M., \& Keil, F. C. (2008). The development of (im)partiality. Cognition, 107, 528-551. doi:10.1016/j.cognition.2007.11.003

Olson, K. R., \& Spelke, E. S. (2008). Foundations of cooperation in young children. Cognition, 108, 222-231. doi:10.1016/j.cognition.2007.12.003

Organ, D.W. (1988) Organizational citizenship behavior: The good soldier syndrome. Lexington Books, Lexington, MA.

Piaget, J. (1932). The moral judgment of the child. Oxford, England: Harcourt Brace.

Reis, H.T., \& Gruzen, J. (1976). On mediating equity, equality, and self-interest: The role of self-presentation in social exchange. Journal of Experimental Social Psychology, 12, 487-503. doi: 10.1016/0022-1031(76)90079-2

Rutland, A., Cameron, L., Milne, A., \& McGeorge, P. (2005). Social norms and selfpresentation: Children's implicit and explicit intergroup attitudes. Child Development, 76, 451- 466. doi:10.1111/j.1467-8624.2005.00856.x

Schmidt, M.F. \& Sommerville, J.A. (2011). Fairness expections and altruistic sharing in 
15-month-old human infants. PLoS ONE, 6, e23223. doi:

10.1371/journal.pone.0023223.g001

Selman, R. L. (1980). The growth of interpersonal understanding: Developmental and clinical analyses. New York: Academic Press.

Shaw, A., DeScioli, P., \& Olson, K.R. (in press). Fairness versus favoritism in children. Evolution and Human Behavior.

Shaw, A. \& Knobe, J. (in press). Not all mutualism is fair, and not all fairness is mutualistic. Behavior and Brain Sciences.

Shaw, A. \& Olson, K.R. (2012) Children discard a resource to avoid inequity. Journal of Experimental Psychology: General, 141, 382-395.

Shaw, A. \& Santos, L. (2012). Lab support for strong reciprocity is weak: Punishing for reputation rather than cooperation. Behavior and Brain Sciences, 35, 39. doi:10.1017/S0140525X11000884

Sigelman, C. K., \& Waitzman, K. A. (1991). The development of distributive justice orientations: Contextual influences on children's resource allocations. Child Development, 62, 1367-1378. doi:10.1111/j.1467-8624

Sloane, S., Baillargeon, R., \& Premack, D. (2012). Do Infants Have a Sense of Fairness? Psychological Science, 23, 196-204. doi :10.1177/0956797611422072

Turiel, E. (2006). The development of morality. In N. Eisenberg, W. Damon, \& R. M. Lerner (Eds.), Handbook of child psychology: Social, emotional, and personality development (pp. 789 - 857). Hoboken, NJ: Wiley. 
Tyler, T.R. (1994). Governing amid diversity: The effect of fair decision-making procedures on the legitimacy of government. Law and Society Review, 28, 809-831. doi:10.2307/3053998

Tyler, T.R., \& Lind, E.A. (1992). A relational model of authority in groups. In M. Zanna (Ed.), Advances in experimental social psychology, Vol. 25 (pp. 151-191). New York: Academic Press. 
Figures

Figure 1: Percentage of participants who did what was fair in the conditions from Experiments 1 and 2. Each condition has 20 participants. $\dagger p=.055 * p<.05, * * p<.01$

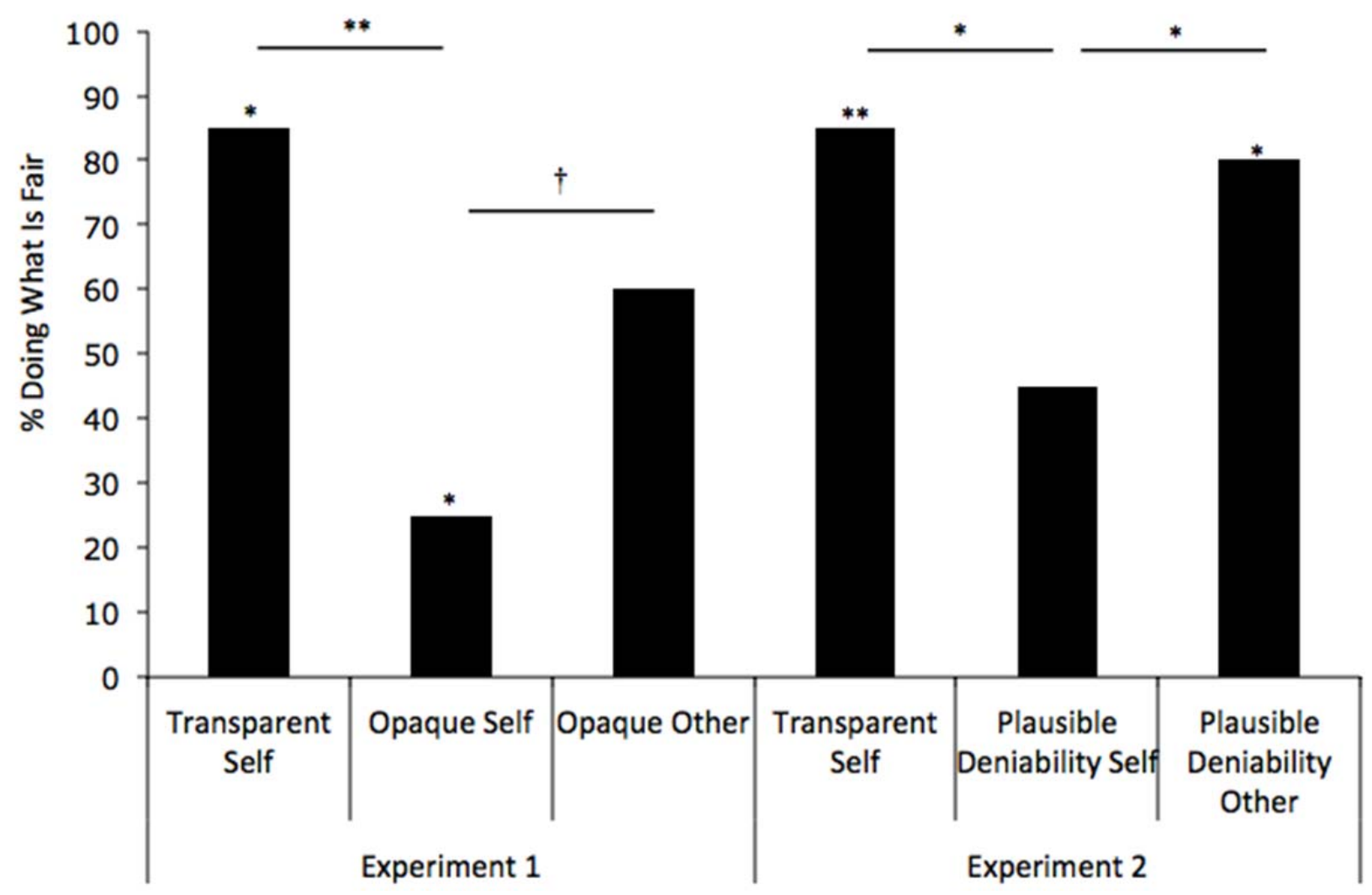


Figure 2. Percentage of children choosing to flip the coin to determine prize assignment as a percentage of children reporting winning the good prize after flipping the coin as a function of age in Experiment 3 (both “Winning the coin flip” bars are significantly above chance, 50\%). $* * * p<.001$

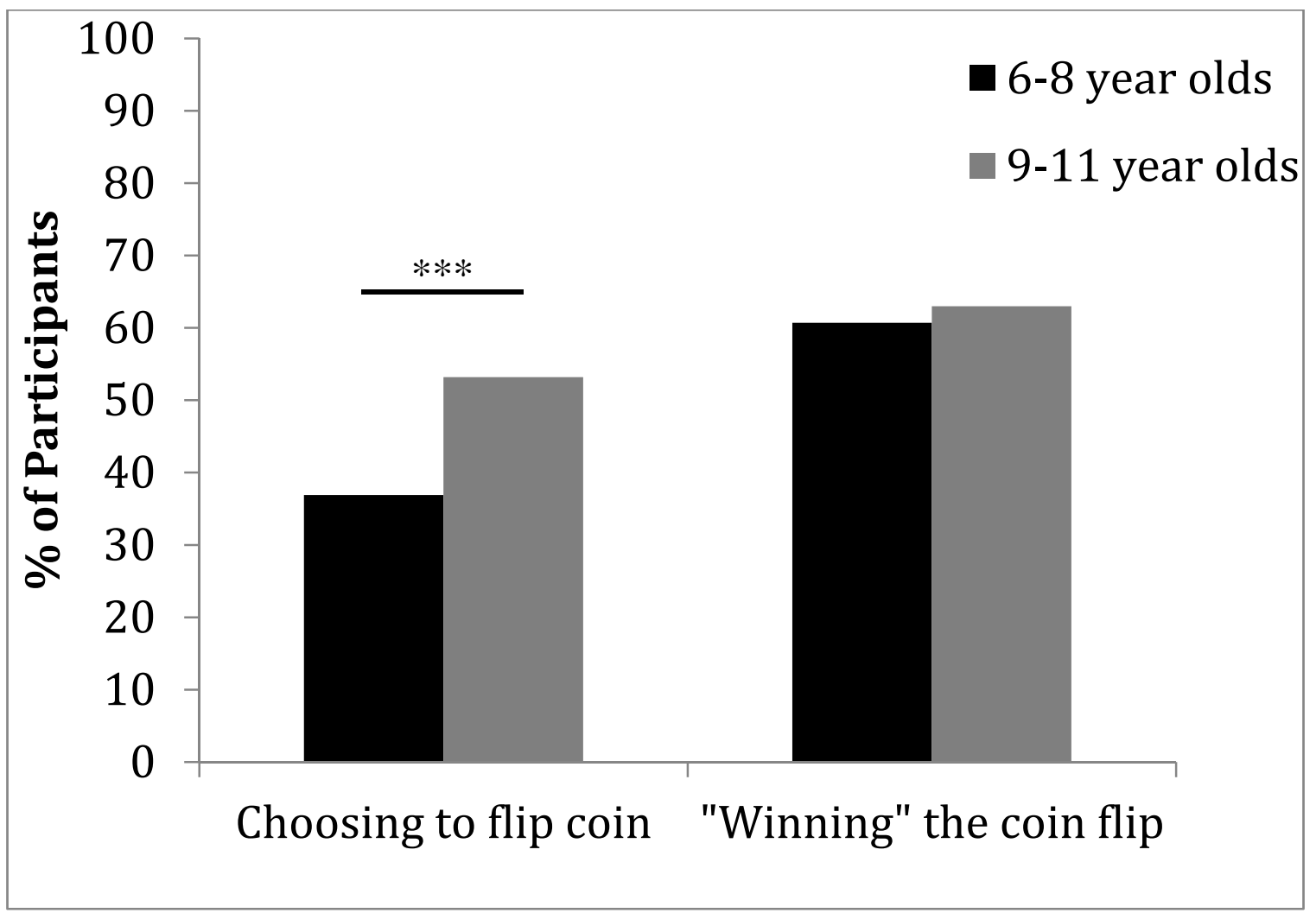

